\title{
Vulneración del principio de corresponsabilidad parental en la legislación
} ecuatoriana

Violation of the principle of parental co-responsibility in Ecuadorian legislation

\author{
Wilson Eduardo Castro-Núñez \\ uq.wilsoncastro@uniandes.edu.ec \\ Universidad Regional Autónoma de los Andes, Quevedo \\ Ecuador \\ https://orcid.org/0000-0003-1405-415X \\ Alba Rosa Pupo-Kairuz \\ uq.albapupo@uniandes.edu.ec \\ Universidad Regional Autónoma de los Andes, Quevedo \\ Ecuador \\ https://orcid.org/0000-0002-1719-9250 \\ Víctor Hugo Tapia-Giler \\ dq.victorhtg27@uniandes.edu.ec \\ Universidad Regional Autónoma de los Andes, Quevedo \\ Ecuador \\ https://orcid.org/0000-0002-0482-7561
}

Recepción: 15 de marzo 2021

Revisado: 25 de mayo 2021

Aprobación: 15 de junio 2021

Publicación: 01 de Julio 2021 


\section{Estimado Editor (a):}

El principio de corresponsabilidad parental se fundamenta en que ambos padres son individualmente aptos para el cuidado y crianza de sus hijos. No obstante, según él Código de la Niñez y Adolescencia(2003), no aplica del todo este principio, puesto que se le brinda preferencia a la madre que al padre. Dando en ciertos casos exclusividad al cuidado de la madre. Por este motivo, se presenta como una tenencia compartida siendo la mejor solución.

En este sentido, para Espinoza Encarnación et al, (2020):

Por otra parte, es importante resaltar que la custodia compartida, guarda relación directa con el principio de corresponsabilidad parental, la Constitución de la República y los tratados internacionales de derechos humanos lo han definido como, las obligaciones que tienen los progenitores, en velar por los cuidados del menor, asistiéndolo, alimentándolo, educándolo y participando de su crianza de manera equitativa. (p.439)

Por otra parte, tiene su reconocimiento en la Convención Internacional sobre los Derechos del Niño en el artículo 18, que establece lo siguiente: Los Estados partes pondrán el máximo empeño en garantizar el reconocimiento del principio de que ambos padres, tengan obligaciones comunes en lo que respecta a la crianza y el desarrollo del niño. (Convención sobre los derechos de los Niños, 2017)

En tal sentido, la Convención Internacional sobre los Derechos del Niño, reconoce y garantiza el desarrollo integral de los menores, puesto que obliga a los Estados a que cumplan con sus disposiciones, en el único beneficio de los niños y la familia. La corresponsabilidad parental sería, junto a otras directrices, como la coparentalidad y la igualdad entre hombre y mujer un principio que informa la custodia compartida (Lathrop Gómez, 2009 citado por Acuña San Martin (2013, p.27).

Así mismo en base al bienestar integral de los niños menores de edad el vínculo afectivo es de suma importancia ya que debe de ser permanente este deber, así mismo estable y armónico, esto en relación con sus padres, para su desarrollo personal, garantizado en la carta magna y en los convenios internacionales. Sin embargo, según Briz (2018), cuando una pareja se separa o se divorcia "es inevitable 
que este hecho genere dolor y afecte a sus integrantes, especialmente a los hijos, que son quienes por lo general sienten más las consecuencias de estos cambios" (p. 2). Es importante destacar, que los titulares de los derechos son los niños, niñas y adolescentes, padre y madre son quienes deben ser corresponsables por el bienestar de los hijos, ya que la Corresponsabilidad Parental está consagrada en la Constitución de la Republica y se encarga de hacer cumplir el bienestar integral de los niños, niñas y adolescentes. Al respecto, Zaidán Albuja(2016) indican que:

En los instrumentos internacionales de derechos humanos y en las constituciones de los Estados no suele reconocerse el derecho de cuidado de los hijos. La razón que lo explica seguramente radica en que las disposiciones sobre la familia ya contienen responsabilidades para los padres que suponen el implícito reconocimiento del derecho. Sin embargo, aquello no es suficiente, el cuidado a los hijos merece la configuración de un derecho a su favor. (p.31)

Se considera necesario que se lleve a cabo una mediación obligatoria entre los padres de los menores de edad que vaya acompañada de terapia familiar para todos, ya que ante una ruptura los menores de edad son los más afectado dejando secuelas negativas psicológicas, porque no sabe que le deparara el destino y lo que sucederá con sus progenitores. Por ende, Herrera y Lathrop (2017) plantean:

En lo que concierne a la relación jurídica entre progenitores e hijos, conocida de manera contemporánea como "responsabilidad parental", el derecho de familia latinoamericano se ha concentrado, principalmente, en los efectos derivados de la ruptura de la pareja (matrimonial o no) en los hijos: alimentos, cuidado personal y régimen de comunicación. De manera crítica, se puede afirmar que no existe un fuerte desarrollo dogmático ni jurisprudencial sobre el concepto y los principios propios de esta institución. (146)

La Custodia Compartida tiene como única finalidad velar por el interés de los menores de edad, de forma que los progenitores participen en la crianza y desarrollo de los menores de edad, sin que uno de los progenitores se sienta desplazado y solo sea una fuente económica. Siendo la Custodia Compartida muy beneficiosa para los niños.

\section{FINANCIAMIENTO}

No monetario. 


\section{AGRADECIMIENTO}

A la Universidad Regional Autónoma de los Andes, Ecuador; por motivar el desarrollo de la Investigación.

\section{REFERENCIAS CONSULTADAS}

Acuña San Martín, M. (2013). El principio de corresponsabilidad parental. [The principle of parental co-responsibility]. Revista de derecho Coquimbo, 20(2), 2159. https://dx.doi.org/10.4067/S0718-97532013000200002

Asamblea Nacional Constituyente de la República del Ecuador, (2008). Constitución de la República del Ecuador. Montecristi. Registro Oficial 449 de 20-oct-2008. Recuperado de https://n9.cl/sia

Congreso Nacional. (2003). Código de la niñez y adolescencia. [Childhood and Adolescence Code]. Quito.

Briz, M. (2018) La mediación y el Síndrome de Alienación Parental. [Mediation and the Syndrome of Parental Alienation] Revista de Mediación, 11(2), 1-8. Recuperado de: https://n9.cl/erbt0

Espinosa Encarnación, M., Pucha Peláez, B., y Ramón Merchán, M., (2020). La custodia compartida un paliativo al Síndrome de Alienación parental. [ Joint custody is a palliative to Parental Alienation Syndrome]. Conrado, 16(73), 434441. Recuperado de: https://n9.cl/3zerd

Herrera, M. y Lathrop, F. (2017). Relaciones jurídicas entre progenitores e hijos desde la perspectiva legislativa latinoamericana. [ Legal relations between parents and children from the Latin American legislative perspective]. Revista de Derecho Privado, (32), 143-173. https://doi.org/10.18601/01234366.n32.06

Naciones Unidas (2017) Convención sobre los Derechos del Niño. [ Convention on the Rights of the Child]. Recuperado de: https://n9.cl/xuugd

Zaidán Albuja, S. (2016) El derecho constitucional de cuidado de los hijos: normativa. [ The constitutional right to care for children: normative]. Tesis de Maestría en Derecho Constitucional. Universidad Andina Simón Bolívar Sede Ecuador. Recuperado de: https://n9.cl/e34sk 